\title{
Optimization of Conditions for the Preparation of Activated Carbon from Lapsi (Choerospondias axillaris) Seed Stone Using $\mathrm{ZnCl}_{2}$
}

\author{
Rinita Rajbhandari Joshi \\ Department of Science and Humanities, Pulchowk Campus \\ Institute of Engineering, Tribhuvan University Nepal
}

\begin{abstract}
Activated carbon was prepared from Lapsi (Choerospondias axillaries ) seed stone by chemical activation method using $\mathrm{ZnCl}_{2}$. The effect of experimental variables; $\mathrm{ZnCl}_{2}$ ratio, temperature and carbonization time on the quality of the activated carbon were systematically invested by determining the carbon yield, iodine number, methylene blue number, surface area and pore volume. Lapsi seed stone powder (LSP) of particle size $<300 \mu \mathrm{m}$ was used to prepare activated carbon under $\mathrm{N}_{2}$ atmosphere. An increase in $\mathrm{ZnCl}_{2}$ ratio in general increased the iodine number and methylene blue number, but on increasing zinc chloride above 50 percentages, iodine and methylene blue number increased only marginally. An increase in carbonization temperature increases the iodine number, methylene blue number, and surface area and pore volume. Increase in carbonization time from 3 hour to 4 hour increases iodine number and methylene blue number and thereafter the increase in iodine number and methylene blue number is gradual. Regarding the carbon yield, it decreases with the $\mathrm{ZnCl}_{2}$ ratio above 50 percent, and the yield also decreases with increase in temperature and carbonization time. Therefore the optimum conditions for the preparation of activated carbon from Lapsi seed stone using $\mathrm{ZnCl}_{2}$ as follows: carbonization temperature of $400^{\circ} \mathrm{C}$, zinc chloride ratio as LSP: $\mathrm{ZnCl}_{2}$ equals $1: 1$, and carbonization time of 4 hour. This resulted an activated carbon with 791 iodine number, 364 methylene blue number, 1167 surface area and 0.65 pore volume.
\end{abstract}

Key words: activated carbon, Lapsi seed, iodine number, methylene blue number, surface area

\section{Introduction}

Lapsi (Choerospondias axillaris) is an indigenous fruit tree of Nepal. It is a wild large deciduous and dioecious plant belonging to the family Anacardiaceae. The edible part of the fruit (skin and pulp) comprises $71 \%$ and seed stone of $29 \%$ [1]. The seed is not a consumable part of Lapsi and is usually discarded as waste. To make better use of cheap and abundant agricultural waste, it is proposed to convert Lapsi seed into activated carbon. This conversion will address problems of unwanted agricultural wastes been converted into useful, value- added adsorbent and also the use of agriculture by- products to represent potential source of adsorbent which will largely address problems of waste management and will have positive impact in the industry based on Lapsi fruit.

Activated carbon has become one of the most technically important and most widely used adsorbents because of its high adsorptive capacity. The high adsorption capacities of activated carbons are related to the properties like surface area, pore volume and pore size distribution. These 
unique characteristics depend on the type of precursors used for the preparation of activated carbon and the preparation conditions [2]. Present technology demands a large production of activated carbons with appropriate characteristics for application in drinking water purification, waste-water treatment and chemical processing.

\section{Literature}

In general, an activated carbon which is used in any of the most common applications must have adequate adsorptive capacity as well the cost of activated carbon must be low for wide spread application. Bevla et al [3], prepared activated carbon from almond shells by chemical activation with $\mathrm{H}_{3} \mathrm{PO}_{4}, \mathrm{~K}_{2} \mathrm{CO}_{3}, \mathrm{Na}_{2} \mathrm{CO}_{3}$ and $\mathrm{ZnCl}_{2}$. They found that activated carbon prepared by using $\mathrm{ZnCl}_{2}$ as activating agent was best with highest adsorption capacity. Activated carbon can be prepared from fruit seeds, agricultural byproducts and any other lignocellulosic materials. Coconut shell, almond and pecan shell, pistachio nut shell, apricot stone, olive, sugar beet pulp, tamarind wood $[4,5,6,7,8,9,10]$ etc. have been extensively used for the preparation of activated carbon. As far as known, no study has been carried out using carbon yield, iodine number and methylene blue number approach in analyzing the production process of activated carbon from Lapsi seed stone using $\mathrm{ZnCl}_{2}$ as activating agent.

A good quality activated carbon should have high iodine number and methylene blue number. As the Iodine number and methylene blue number increase, the surface area also increases. The iodine number correlates with surface area [11]. Bacaoui et al, [12] reported that for economic viability, activated carbon should have a surface area of $1000-1300 \mathrm{~m} 2 / \mathrm{g}$. Activated carbon had been prepared from Lapsi seed stone power by chemical activation with Zinc Chloride and its characterization by SEM,TEM, FTIR, XRD, Raman, BET isotherm and its application for the adsorption of arsenic from water were done [13, 14,].In the present study, the optimal experimental conditions; carbonization temperature, activation time, activating agent, $\mathrm{ZnCl}_{2}$ ratio required to prepare activated carbons from Lapsi seed stone by correlating with the yield of activated carbons, iodine number and methylene blue number is presented.

\section{MATERIALS AND METHODS}

\subsection{Materials}

Lapsi, (choreospondiasAxillaris), were collected from vegetable market at Kalimati, Kathmandu. The fleshly part of this fruit was removed and the seed stones were washed several times with distilled water and dried in electric oven at $110^{\circ} \mathrm{C}$ for 6 hours. Then the well dried seed stones were crushed and grinded in an electric grinder and sieved to obtain the particles of uniform size $300 \mu \mathrm{m}$ as Lapsi seed Powder (LSP). Zinc chloride of purity higher than $98 \%$ was used from Qualigen. The nitrogen is of ultra high pure (UHP) grade.

\subsection{Methodology}

\subsubsection{Preparation of activated carbon}

The Lapsi seed powder (LSP) of particle size of $300 \mu \mathrm{m}$ was treated with $\mathrm{ZnCl}_{2}$ in the ratio from LSP: $\mathrm{ZnCl}_{2}=1: 0.25(\mathrm{AC}-0.25), 1: 0.50(\mathrm{AC}-0.50), 1: 1(\mathrm{AC}-1), 1: 2(\mathrm{AC}-2)$ and 1:4 (AC - 4) and left for 24 hours. Then the mixtures were heated in hot plate till dry mass was obtained. The dry mass was transferred to a quartz tube and placed in horizontal tubular furnace (Accumax, India) and carbonized at different temperature from $400^{\circ} \mathrm{c}$ to $800^{\circ} \mathrm{C}$ and carbonization time from 3hour to 6 
130 Optimization of Conditions for the Preparation of Activated Carbon from Lapsi (Choerospondias axillaris) .......

hour (table 3.1 ) in continuous flow of nitrogen gas at flow rate of $100 \mathrm{~mL} /$ minute The product was cooled to room temperature and treated with $0.1 \mathrm{M} \mathrm{HCl}$, and then washed with distilled water till free from zinc ion, and the $\mathrm{pH}$ value of the final rinsed water was between $\mathrm{pH}$ 6-7. The resulting carbons were then dried in an electric oven at $110^{\circ} \mathrm{C}$ for 3 hours. The well dried activated Carbon (AC) was sieved and material of particle size $106 \mu \mathrm{m}$ was used for further investigations. Care was taken to ensure the material was not forced through the sieve by hand pressure.

Table 3.1 Preparation of activated carbon activated with different ratio of $\mathrm{LSP}: \mathrm{ZnCl}_{2}$ carbonized for 4 hours at different temperature

\begin{tabular}{|l|l|l|l|l|l|}
\hline \multirow{2}{*}{ S. N. } & \multirow{2}{*}{ LSP:ZnCl2 } & \multicolumn{2}{|c|}{ Weight in gram } & \multicolumn{1}{c|}{$\begin{array}{c}\text { Carbonization } \\
\text { temperature o C }\end{array}$} & Activated carbon \\
\cline { 3 - 4 } & & \multicolumn{1}{|c|}{ LSP } & \multicolumn{1}{|c|}{$\mathbf{Z n C l}_{2}$} & \\
\hline 1 & $1: 0.25$ & 100 & 25 & 400 & AC-0.25 \\
\hline 2 & $1: 0.5$ & 100 & 50 & 400 & AC-0.5 \\
\hline 3 & $1: 1$ & 100 & 100 & 400 & AC-1 \\
\hline 4 & $1: 2$ & 50 & 100 & 400 & AC-2 \\
\hline 5 & $1: 4$ & 25 & 100 & 400 & AC-4 \\
\hline 6 & $1: 0.5$ & 100 & 50 & 600 & 6 AC-0.05 \\
\hline 7 & $1: 1$ & 100 & 100 & 600 & 6 AC-1 \\
\hline 8 & $1: 2$ & 50 & 100 & 600 & 6 AC-2 \\
\hline 9 & $1: 0.5$ & 100 & 50 & 800 & 8 AC-0.05 \\
\hline 10 & $1: 1$ & 100 & 100 & 800 & 8 AC-1 \\
\hline 11 & $1: 2$ & 50 & 100 & 800 & 8 AC-2 \\
\hline
\end{tabular}

To study the optimum carbonization time, $\mathrm{LSP}: \mathrm{ZnCl}_{2}$ were mixed in 1:1 ratio and carbonized at $400^{\circ} \mathrm{C}$ for different time as in table 3.2.

Table 3.2: Activated carbons prepared at the same ratio i.e. $\mathrm{LSP}: \mathrm{ZnCl}_{2}$ equal to 1:1 carbonized at $400{ }^{\circ} \mathrm{C}$ for different time.

\begin{tabular}{|l|l|l|}
\hline \multicolumn{1}{|c|}{ S.N. } & \multicolumn{1}{|c|}{ Carbonization time in hour } & \multicolumn{1}{c|}{ Activated carbon } \\
\hline 1 & 3 & AC-1 (3h) \\
\hline 2 & 4 & AC-1 (4h) \\
\hline 3 & 5 & AC-1 (5h) \\
\hline 4 & 6 & AC-1 (6h) \\
\hline
\end{tabular}

To study the optimum carbonization temperature, $\mathrm{LSP}: \mathrm{ZnCl}_{2}$ were mixed in 1:1 ratio and carbonized for 4 hour at different temperatures as in table 3.3. 
Table 3.3.Activated carbons prepared with the same ratio i.e. $\mathrm{LSP}: \mathrm{ZnCl}_{2}$ equal to $1: 1$ carbonized for 4 hour at different temperature.

\begin{tabular}{|l|l|l|}
\hline \multicolumn{1}{|c|}{ S.N. } & \multicolumn{1}{|c|}{ Carbonization Temperature $^{\mathbf{0}} \mathbf{C}$} & \multicolumn{1}{c|}{ Activated carbon } \\
\hline 1 & 300 & $3 \mathrm{AC}-1$ \\
\hline 2 & 400 & $4 \mathrm{AC}-1$ \\
\hline 3 & 500 & $5 \mathrm{AC}-1$ \\
\hline 4 & 600 & $6 \mathrm{AC}-1$ \\
\hline 5 & 700 & $7 \mathrm{AC}-1$ \\
\hline 6 & 800 & $7 \mathrm{AC}-1$ \\
\hline
\end{tabular}

\subsubsection{Yield of Activated carbon}

The yield of activated carbon is regarded as an indicator of the process, efficiency for the chemical activation process. The yield of activated carbon (AC) was calculated on a chemical free basis. The yield of $\mathrm{AC}$ was calculated as the percentage weight of the resultant activated carbon divided by weight of dried Lapsi seed powder.

$$
\begin{aligned}
\text { Yield }(\%)=\frac{\text { Weight of activated carbon after carbonization }}{\text { Weight of lapsi seed powder }} \\
\frac{\text { Weight of activated carbon after carbonization }}{\text { Weight of lapsi seed powder }}
\end{aligned}
$$

\subsubsection{Determination of Iodine Number}

Iodine number $\left[\mathrm{mg}^{2} / \mathrm{g}\right]$ indicates the extent of micro pore distribution in the carbon. It is defined as the milligram of iodine adsorbed by $1.0 \mathrm{~g}$ of carbon. The iodine number correlates with surface area [11]. The iodine number is determined according to the ASTM D4607, 2006 method [15]. In this method, $100 \mathrm{mg}$ of activated carbon was added to $5 \mathrm{~mL}$ of $5 \% \mathrm{HCl}$ and then boiled and cooled. To the cooled solution $10 \mathrm{~mL}$ of $0.1 \mathrm{~N}$ iodine solution was added, shaken for 30 second and filtered. The filtrate was titrated with $0.1 \mathrm{~N}$ sodium thiosulphate solutions with starch as an indicator. The iodine number is determined by the following formula.

$$
\text { Iodine Number }=\frac{\text { Amount of iodine adsorbed by carbon }}{\text { Weight of carbon taken in gram }}
$$

\subsubsection{Determination of Methylene blue number}

Methylene blue number $\left[\mathrm{mg}^{2} / \mathrm{g}\right]$ indicates the extent of meso pore distribution in the carbon. The methylene blue (MB) is the maximum amount of dye adsorbed on $1.0 \mathrm{gm}$ of adsorbent. For the determination of Methylene blue number (MBN) of activated carbon, $0.05 \mathrm{~g}$ of activated carbon was added to $100 \mathrm{ml}$ of $\mathrm{MB}$ of concentration $100 \mathrm{ppm}$ and then equilibrated for 3 hours at $200 \mathrm{rpm}$. Then the solution was filtered through filter paper Whatman 41, and the remaining concentration of methylene blue was determined by measuring the absorbance at $664 \mathrm{~nm}$ using a UV/Vis spectrophotometer (CECIL-CE-100). 
The Methylene blue number was calculated by the following equation (Raposo et al, 2009).

$$
\operatorname{MBN}\left(\frac{m g}{g}\right)=\frac{\left(C_{o}-C_{\theta}\right)}{M} \times V \operatorname{MBN}\left(\frac{m g}{g}\right)=\frac{\left(C_{o}-C_{\theta}\right)}{M} \times V
$$

where,

$\mathrm{M}=$ mass of activated carbon in gram

$\mathrm{V}=$ volume of test solution in litre

$\mathrm{Co}=$ initial concentration of $\mathrm{MB}$

$\mathrm{Ce}=$ concentration of $\mathrm{MB}$ at equilibrium

\subsubsection{Nitrogen Adsorption-Desorption}

Surface areas, pore volumes and pore size distributions were evaluated from nitrogen adsorptiondesorption isotherms by Brunauer, Emmett and Teller (BET), method by recording $\mathrm{N}_{2}$ adsorption desorption isotherms. The measurements were carried out in an automatic adsorption instrument (Quantachrome Instrument, Autosorb-1 USA). For each measurement about $20 \mathrm{mg}$ of activated carbon was taken and degassed for $24 \mathrm{~h}$ at $100{ }^{\circ} \mathrm{C}$ prior to the measurement. The adsorptiondesorption isotherms were recorded at liquid nitrogen temperature $77.35 \mathrm{~K}$.

\section{Preparation of the reagents}

1. $0.1 \mathrm{~N}$ Iodine solution: It was prepared by dissolving $3.175 \mathrm{gm}$ of iodine in $10 \% \mathrm{KI}$ and diluted the solution in distilled water to $250 \mathrm{~mL}$.

2. $5 \% \mathrm{HCl}$ : It was prepared by dissolving $5 \mathrm{ml}$ of conc $\mathrm{HCl}$ in distilled water and diluted to 100 $\mathrm{mL}$.

3. $0.1 \mathrm{M}$ Sodium thiosulphate: It was prepared by dissolving $6.2 \mathrm{gm}$ sodium thiosulphate in distilled water to $250 \mathrm{~mL}$.

4. $1 \%$ Starch solution: It was prepared by dissolving $1.0 \mathrm{gm}$ starch in distilled water to $100 \mathrm{~mL}$ and heated to boil.

5. $100 \mathrm{ppm}$. Methylene blue: It was prepared by dissolving $100 \mathrm{mg}$ methylene blue in distilled water to $1000 \mathrm{~mL}$.

\section{Results and Discussions}

\subsection{The Yield of Activated carbon}

\section{The Yield of Activated carbon (AC-1) at different carbonization temperature}

The figure 4.1 shows the percentage yield of activated carbons as a function of carbonization temperature. The yield decreased continuously with the increase of carbonization temperature. 


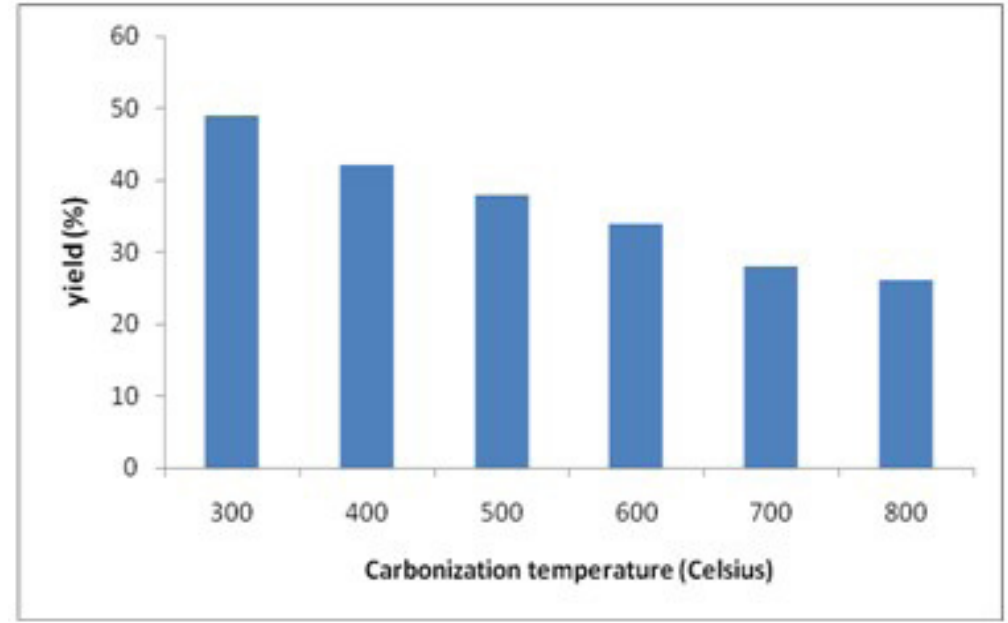

Figure 4.1.The yield of activated carbons at different carbonization temperature

The decrease in yield at high temperature may be due to the release of oxygen and hydrogen as $\mathrm{CO}, \mathrm{CO}_{2}$ and $\mathrm{CH}_{4}$ from lignocellulosic materials rather than $\mathrm{H}_{2} \mathrm{O}$ [16].

\section{The yield of activated carbons (AC-1) at different carbonization time}

The figure 4.2 shows percentage yield as a function of carbonization time. The percentage yield of activated carbon decreased with the increase of carbonization time. The yield decreased at longer carbonization times because of the higher carbon burn-off [17] and attributed to the release of carbon and hydrogen in the form of $\mathrm{CO}, \mathrm{CO}_{2}, \mathrm{CH}_{4}$ and hydrocarbon from lignocelluloses materials rather than as $\mathrm{H}_{2} \mathrm{O}$.

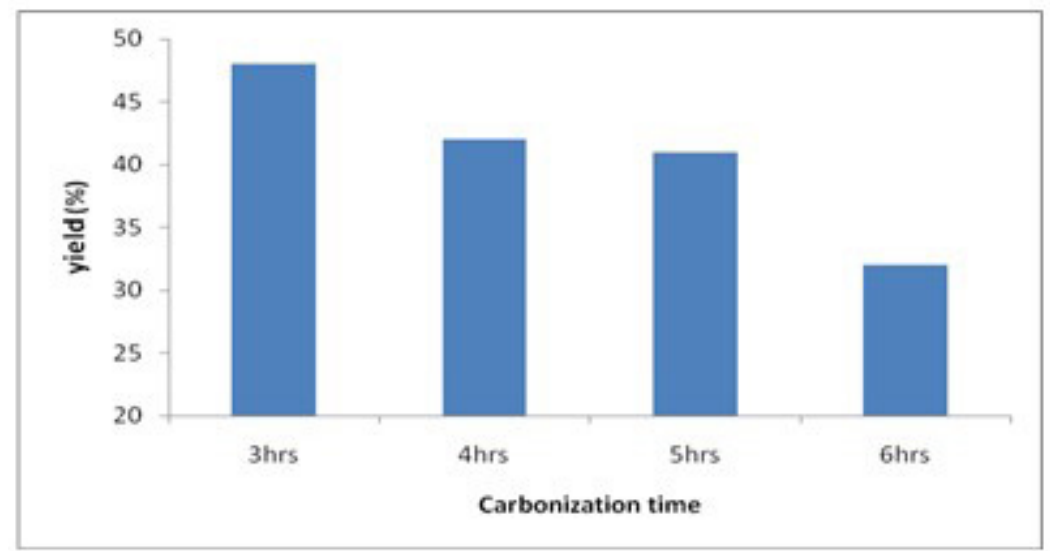

Figure 4.2.The yield of activated carbons at different carbonization time

\section{The yield of activated carbons with different ratio of $\mathrm{ZnCl}_{2}$}

In the figure 4.3, it is observed that on increasing the ratio of activating agent, $\mathrm{ZnCl}_{2}$ the percentage yield decreases due to the increase release of volatile matter from the sample. The lower yield with the higher activating agent might be caused by the enhancement of carbon burn-off by extra activating agent [17]. 


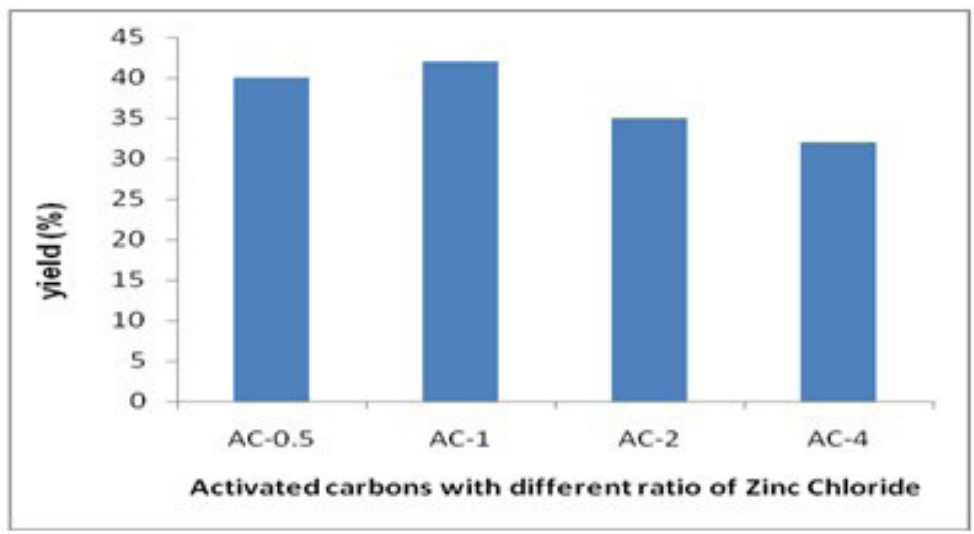

Figure 4.3. The yield of activated carbons with different ratio of $\mathrm{ZnCl} 2$

\subsection{Iodine number and Methylene blue number}

The Iodine number of the activated carbons from Lapsi seed stone chemically activated with zinc chloride in different ratio at different carbonization temperature is given in figure 4.4.

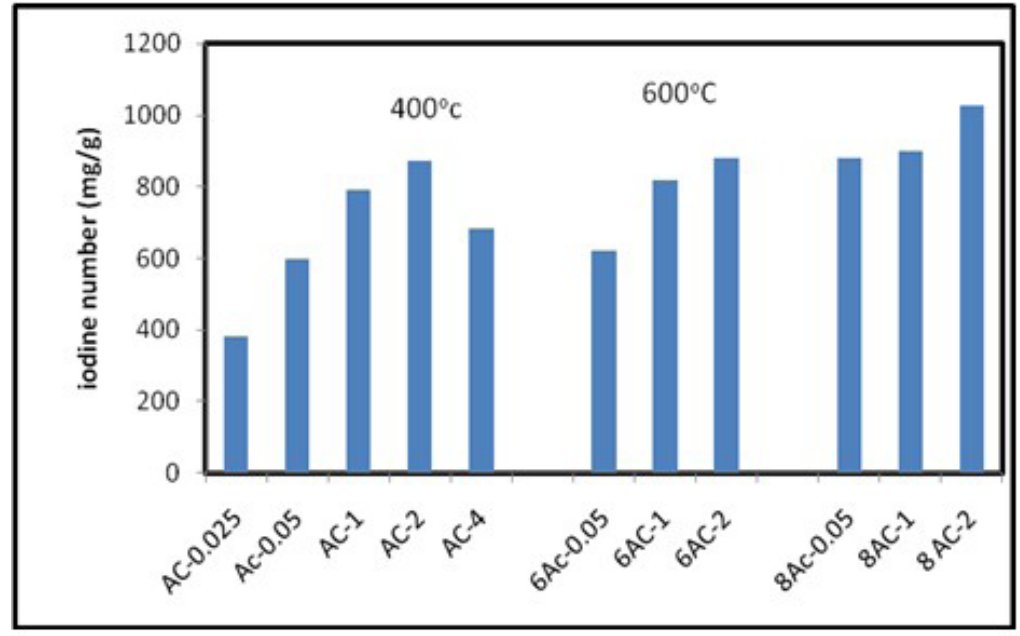

Figure 4.4: Iodine number of the activated carbons from Lapsi seed stone with different ratio of $\mathrm{ZnCl}_{2}$ at different temperatures.

The figure 4.4 clearly shows that the increase in amount of zinc chloride, as an activating agent, increased the iodine number of the activated carbons. With the increase in $\mathrm{ZnCl}_{2}$, this activating agent enters into the interior of the particles whereby it acts as a template for the creation of the microporosity, therefore high concentration of activating agent induces the formation of more micropores in the carbon resulting higher iodine number of the activated carbons up to LSP: $\mathrm{ZnCl}_{2}$ equal to $1: 2$. .

The figure 4.4 also shows that at higher temperature of carbonization increases the iodine number, this is because increase in temperature increases distillation of tar from the carbon thereby releasing more micro pores in the resultant product. 
Thus higher amount of zinc chloride as an activating agent and higher carbonization temperature both are favorable for the preparation of activated carbons from the Lapsi seed stone. High temperature carbonization has some disadvantage as well, firstly the yield will be low owing to the removal of carbon with $\mathrm{O}$ and $\mathrm{H}$ (as $\mathrm{CO}_{\mathrm{x}}$ and hydrocarbons) and the energy required for carbonization will be higher which results the increase of the cost of production of activated carbon.

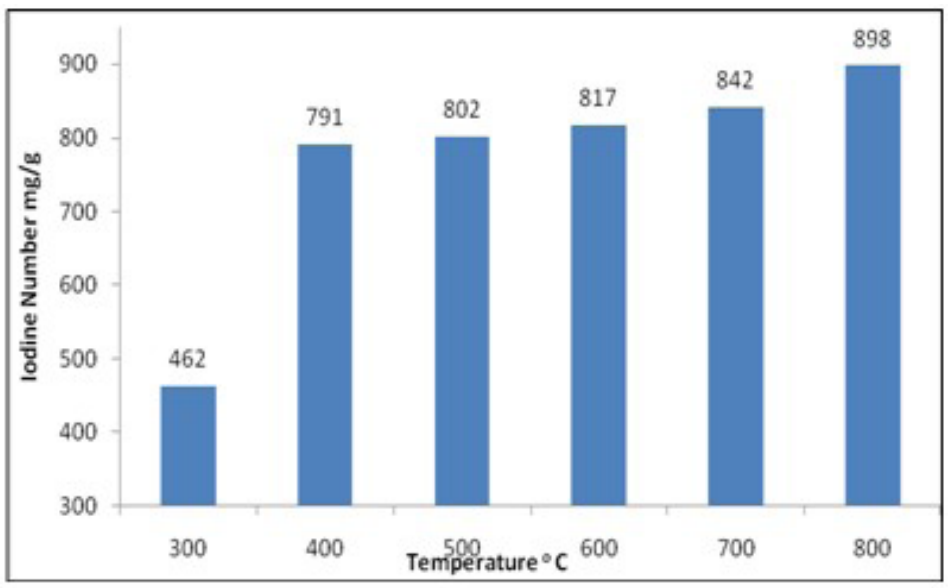

Figure 4.5 Effect of carbonization temperature on iodine number

The figure 4.5 shows the iodine number of activated carbon prepared by keeping the ratio of $\mathrm{LSP}: \mathrm{ZnCl}_{2}$ equal to $1: 1$ at different carbonization temperature. At carbonization temperature $300^{\circ} \mathrm{C}$ the iodine number is quite low. This may be due to incomplete charring of the lignocellulosic material. The product at this temperature is not a pure carbon but a mixture of the char and undecomposed precursor. When temperature is increased from $300^{\circ} \mathrm{C}$ to $400^{\circ} \mathrm{C}$, the iodine number increased significantly from 462 to 791 . At this temperature the decomposition of lignocellulosic material is almost complete as evident by the TGA curve [18]. Increase in iodine number with increase in carbonization temperature above $400^{\circ} \mathrm{C}$ is gradual. This gradual increase in iodine number may be due to increase in distillation of tar which release some pores for adsorption of iodine. This clearly indicated that $400^{\circ} \mathrm{C}$ is the optimum temperature for carbonization of Lapsi seed stone powder to get activated carbon with higher adsorption capacity.

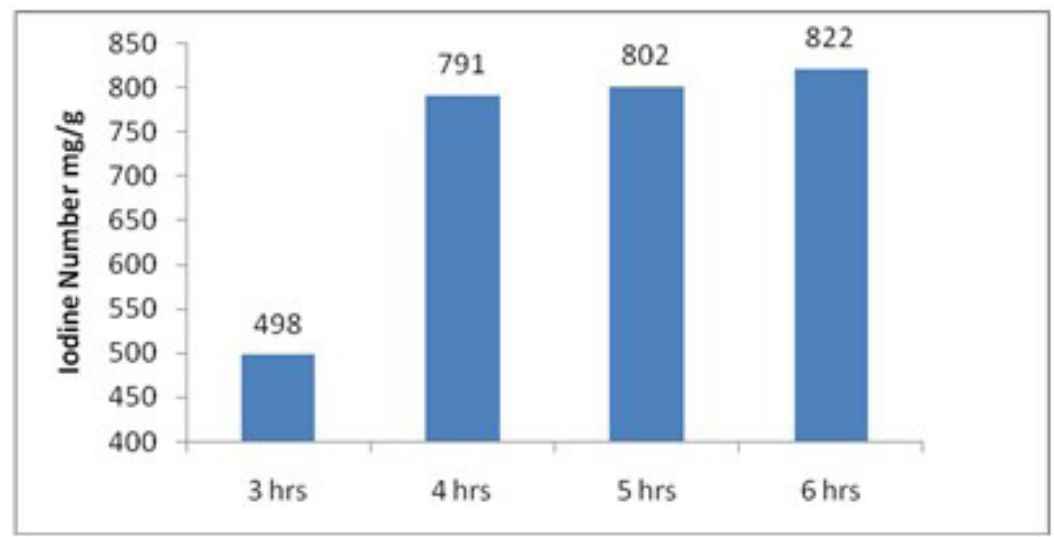

Figure 4.6. Effect of carbonization time on iodine number 
The figure 4.6 shows the effect of carbonization time on the iodine number of carbon prepared at $400^{\circ} \mathrm{C}$ with the ratio of $\mathrm{LSP}: \mathrm{ZnCl}_{2}$ equal to $1: 1$. When the time of carbonization increased from $3 \mathrm{~h}$ to $4 \mathrm{~h}$ the iodine number increased significantly and thereafter the increase is gradual. This means that 4 hour is sufficient to prepare activated carbon from Lapsi seed stone.

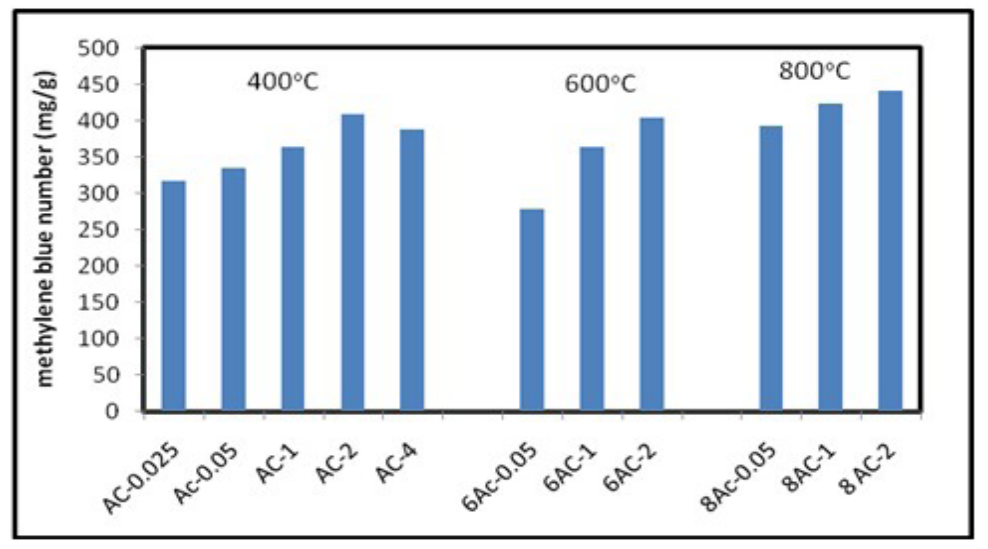

Figure 4.7: Methylene blue number of the activated carbons from Lapsi seed stone with different ratio of $\mathrm{ZnCl}_{2}$ at different temperatures.

The figure 4.7 clearly shows that the increase in amount of zinc chloride, as an activating agent, increased the methylene blue number of the activated carbons. This observation could probably be due to the depolymerization of cellulose resulting in tar formation.

The figure 4.7 also shows that at higher temperature of carbonization, increases the methylene blue number, this is because increase in temperature increases distillation of tar from the carbon thereby releasing more meso pores in the resultant product.

Thus higher amount of zinc chloride as an activating agent and higher carbonization temperature both are favorable for the preparation of activated carbons from the Lapsi seed stone. High temperature carbonization has some disadvantage as well, firstly the yield will be low owing to the removal of carbon with $\mathrm{O}$ and $\mathrm{H}$ (as $\mathrm{CO}_{\mathrm{x}}$ and hydrocarbons) and the energy required for carbonization will be higher which results the increase of the cost of production of activated carbon.

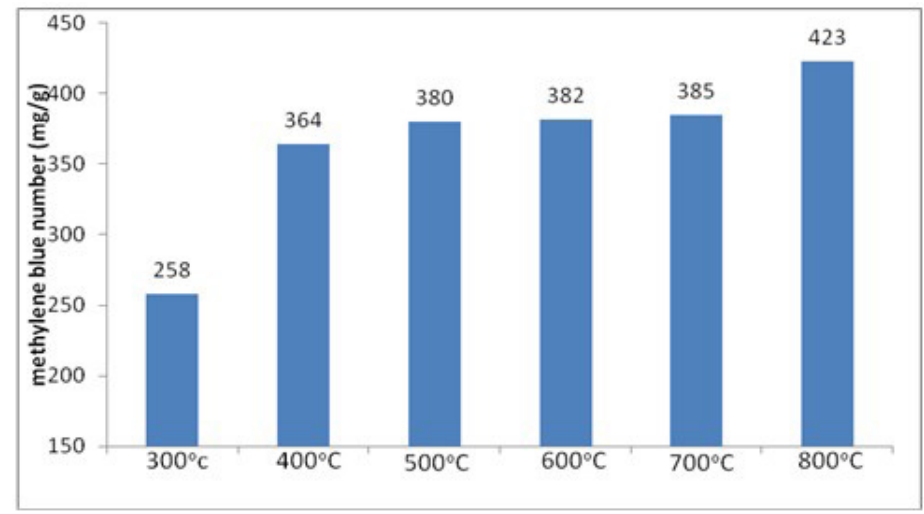

Figure 4.8. Effect of carbonization temperature on MBN 
The above figure 4.8 shows that with increase of carbonization temperature from $300^{\circ} \mathrm{C}$ to $400^{\circ} \mathrm{C}$ the increase of methylene blue number is significant then with further increase in temperature the increase in methylene blue number is marginal.

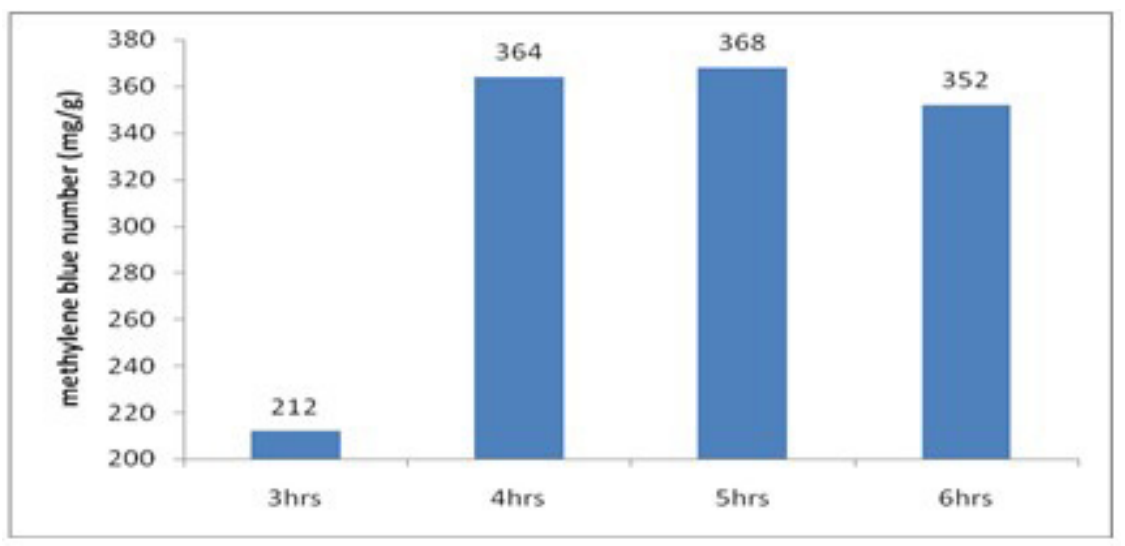

Figure 4.9. Effect of carbonization time on MBN

The figure 4.9 shows the effect of carbonization time on methylene blue number. The increase of methylene blue number is significant when the carbonization time increase from 3 hour to 4 hour. This is perhaps due to the increase in distillation of tar from the product and releasing the mesopores for adsorption of methylene blue molecule. The increase in methylene blue number with further increasing the carbonization time is very little and still increase of carbonization time to 6 hour has decrease the methylene blue number this may be due to the reduction of porosity in the carbon owing to destruction of mesopores producing macropores [19].

\subsection{Nitrogen Adsorption}

Nitrogen adsorption-desorption measurements were conducted to calculate the specific surface area, pore size distribution, and pore volume of the activated carbons is given in table 4.1.

Table 4. 1 Surface area, pore size and pore volume of activated carbons carbonized at different temperature with same ratio asLSP: $\mathrm{ZnCl} 2=1: 1$, carbonized for 4 hours.

\begin{tabular}{|l|l|l|l|l|l|l|}
\hline S.N, & LSP:ZnCl2 & $\begin{array}{l}\text { Carbonization } \\
\text { temperature }{ }^{\circ} \mathrm{C}\end{array}$ & Surface area $\mathrm{m}^{2} / \mathrm{g}$ & $\begin{array}{l}\text { Pore size / } \\
\mathrm{nm}\end{array}$ & $\begin{array}{l}\text { Pore volume } \\
\mathrm{cc} / \mathrm{g}\end{array}$ \\
\hline 1. & $1: 1$ & 400 & 1167 & 2.22 & 0.65 & \\
\hline 2. & $1: 1$ & 600 & 1569 & 2.63 & 1.03 & \\
\hline 3. & $1: 1$ & 800 & 1800 & 2.43 & 1.09 & \\
\hline
\end{tabular}

In above table 4.1 surface area, pore size as well as pore volume was observed to increase with increasing temperature. This observation could probably be due to drastic expansion of the carbon material leading to the creation of large surface area. Similar results were obtained by [20] using sorghums. Generally, as the temperature increase devolatilization also increases which further develop the rudimentary pore structure in the carbon and also enhance the existing pores thus creating higher surface area and higher porosities. Besides, the increase in temperature also caused the $\mathrm{CO}_{2}$ and the surface metal complexes to further gasify the carbon leading to widening of pores and also increases pore volume [21] but control of the activation temperature is of economic interest 
since lower temperature of complete carbonization are generally desired as this is equivalent to reduction in energy consumption.

\section{Conclusion}

The optimum conditions for the preparation of nanoporous activated carbons from Lapsi (choerospondias axillaris) seed stone were determined by studying systematically the effect of Lapsi seed powder/ $\mathrm{ZnCl}_{2}$ ratio, carbonization temperature, carbonization time on yield of activated carbon, iodine number, methylene blue number and BET surface area. The increase in $\mathrm{ZnCl}_{2} /$ Lapsi seed powder ratio in general increased the iodine and methylene blue number indicating the increase in adsorptive capacity and meso and micro porosities in the resulting activated carbon. On increasing LSP:ZnCl2 equals1:1, iodine number and methylene blue number increased only marginally indicating the attainment of equilibrium concentration of nanopores in the carbon. Similarly increasing carbonization time from $3 \mathrm{hrs}$ to $4 \mathrm{hrs}$ there was significant increase in iodine number and methylene blue number and there after the increase is gradual. Likewise increase in iodine number and methylene blue number with increase in carbonization temperature above $400^{\circ} \mathrm{C}$ is gradual. At $400^{\circ} \mathrm{C}$ the decomposition of LSP lignocellulosic material is almost complete as evident by the TGA curve [18]. The BET surface area of activated carbon prepared at $800^{\circ} \mathrm{C}$ is quit higher but the yield of activated carbon at this temperature is so low that it is economically not profitable to prepare activated carbon at this high energy consumption. So it is concluded that the Lapsi seed powder activated with $\mathrm{ZnCl}_{2}$, ratio of $1: 1$, carbonized at $400^{\circ} \mathrm{C}$ for 4 hour is optimum condition for the preparation of activated carbon for further work.

Acknowledgement: The author would also like to express deepest gratitude to Prof. Dr. Raja R Pradhanang, Dr. Lok K Shrestha, and Dr. Bhadra P Pokherel for their valuable suggestions.

\section{References}

[1] Paudel KC, Eder R, Paar E, Pieber K (2002), Chemical composition of Lapsi (Choerospondiasaxillaris) fruit from Nepal, J. Mitteilungen Klosterneuburg, 52, 45-53.

[2] Tan IA, Ahmad AL and Hameed BH (2008), Preparation of activated carbon from coconut husk: Optimization study on removal of 2, 4, 6- trichlorophenol using response surface area method. J. of Haz.Mater. 153, 709- 717.

[3] Bevla F R, Rico D P and Gomis A F M (1984a), Activated carbon from almond shells. chemical activation. 1. Activating reagent selection and 88 variables influence, J. ind. Eng. Chem. Prod. Res. Dev., 23, 266-269.

[4] Hu Z and Srinivasan M P (2001), Mesoporous high-surface-area activated carbon. Microporous and Mesoporous Materials, 43, 267-275.

[5] Toles CA, Marshall WE, Johns MM (1999), Phosphoric acid chemical activation of nutshell for metals and organic remediation: process optimization, J. Chem.Technol.Biotechnol, 72, 255263. [6] Lua A C, Yang T,(2005), Characteristics of activated carbon prepared from pistachionut shell by zinc chloride activation under nitrogen and vacuum conditions. J. of Colloid and Interface Science, 290, 505-513.

[7] Soleimani M and Kaghazchi T (2008), Activated hard shell of apricot stones: a promising adsorbent in gold recovery. Chinese $J$. of Chemical Engineering, 16, 112-118.

[8] Zabaniotou A, Stavropoulos G, Skoulou V (2008), Activated carbon from olive kernels in a two stage process: Industrial improvement. Bioresource Technology, 99, 320-326. 
[9] Özer A and Çam G (2002), The Determination of Surface Area and Color Adsorption Capacity of Activated Carbon from Sugar Beet Pulp Treated with Phosphoric Acid, J. F. Ü. Müh. Bil. Der. 14(1), 191-197.

[10] Sahu J N, Acharya J and Meikap BC (2010), Optimization of production conditions for activated carbons from Tamarind wood by zinc chloride using response surface methodology. Bioresource Technology, 101, 1974-1982.

[11] Olafadehan OA, Jinadu OW, Salami L and Popoola OT (2012), Treatment of brewery wastewater effluent using activated carbon prepared from coconut shell, International Journal of Applied Science and Technology, 2(1):165 - 178.

[12] Bacaoui A, Yaacoubi A, Dahbi C, Bennouna R, Phantanluu FJ and Maldonado- Hodar ( 2001), J. Rivera and C. Moreno- Castilla, Optimization of conditions for the preparation of activated carbons from olivewaste.Carbon.39, 425- 432.

[13] Rajbhandari R, Shrestha LK and Pradhananga RR (2011), Preparation of Activated Carbon from Lapsi Seed Stone and its Application for the Removal of Arsenic from Water. J. Institute of Engineering, 8, 211-218.

[14] Rajbhandari R, Shrestha LK, Pokharel B P and Pradhananga R R (2013), Development of Nanoporous Structure in Carbons by Chemical Activation with Zinc Chloride. J. Nanosci. Nanotechnol, 13, 2613-2623..

[15] American Society for Testing and Materials (2006) Standard test method of determination of iodine number of activated carbon, ASTM Committee on Standards.

[16] March H and Rodriguez-Reinoso F (2006), Activated Carbon, Elsevier, Amsterdam.

[17] Qian Q, Machida M, Tatsumoto H. (2007), Preparation of activated carbons from cattle-manure compost by zinc chloride activation. Bioresource Technology, 98, 353-360.

[18] Rajbhandari R, Shrestha LK and Pradhananga RR ( 2012), Nanoporous Activated Carbon Derived from Lapsi (Choerospondias Axillaries) Seed Stone for the Removal of Arsenic from Water. J. Nanosci. Nanotechnol, 12, 7002-7009.

[19] Caturla F, Molina-Sabio M and Rodriguez-Reinoso F (1991), Preparation of activated carbon by chemical activation with $\mathrm{ZnCl} 2$. Carbon, 29, 999-1007.

[20] Diao Y, Walawender WP and Fan LT (2002), Activated carbons prepared from phosphoric acid activation of grain sorghum. Bioresource. Technol. 81, 45- 52.

[21] Wu FU and Teng RL (2006), Preparation of highly porous carbon from fire wood by KOH etching and $\mathrm{CO}_{2}$ gasification for adsorption of dyes and phenols from water. J. of Colloid Interface Sci. 294, 21- 30 . 